\title{
Oculomotricity in childhood: is the normal range the same as in adults?
}

\section{Raquel Mezzalira ${ }^{1}$, Liliane Coelbo Neves ${ }^{2}$, Oscar Antonio Queiroz Maudonnet ${ }^{3}$, Marcia Maria do Carmo Biléckí, Fernanda Gobbi de Ávila}

Key words: oculomotricity, adults, childhood.

\section{Summary}

r he study of oculomotricity is done by the evaluation of three systems: saccade eye movements (MOS), optokinetic nystagmus (NO) and smooth pursuit eye movement (MORL). The joint action of these three systems allows the visual field's establishment in different movement situations. Aim: To compare the value of oculomotricity in normal adults and children to confirm, or not if it is viable to use the same parameters of adults normality to children's exams interpretation. Study design: clinical with transversal cohort. Material and Method: We studied MOS, NO and MORL in 50 normal children and in 35 adults and the results were compared by the t Student test. Results: The data analysis showed significant difference between children and adults (significance at level $\pm=0.05$ ) Discussion: In the literature we have found evidence that myelinization of the vestibular pathways happen at about 16 weeks and the pyramidal tracts, at 24 months. Oculomotricity is finished at this time. Other papers describe the importance of these tests in the diagnostic of neurological diseases, visual alterations and as predictors of the risk of schizophrenia development but they do not report the normal range in children. In our study we found increased latency of MOS, increase in gain of NO, reduction in gain and increase in the distortion of MORL in children if compared to adults, which is in accordance with the literature. These alterations can be explained by the low attention during the tests and the immaturity of ocular movements' control in children. Conclusion: Therefore, the establishment of a parameter of normality to the oculomotricity in childhood is necessary for the correct analysis of the oculography to avoid misinterpretation of the exam.

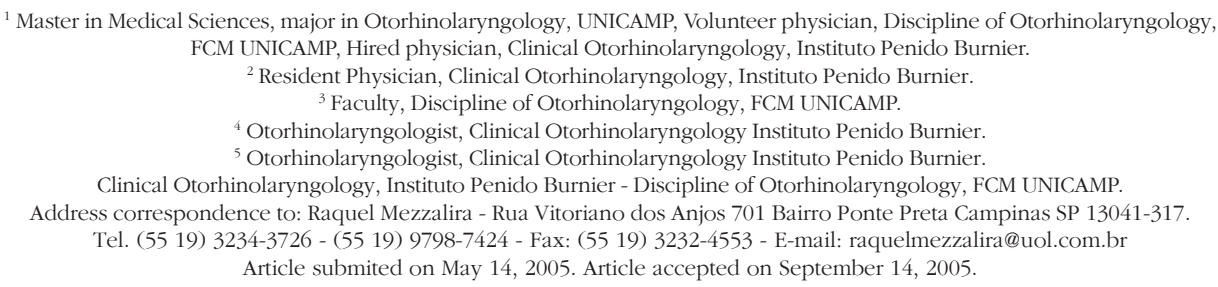




\section{INTRODUCTION}

The look is resultant from head and ocular movements directed to centralizing the image of an object over the fovea. Phasic and tonic movements of the head search for the visual target and stabilize the image over the fovea.

The study of oculomotricity is defined through the assessment of three movements: saccadic eye movement (MOS), optokinetic nystagmus (NO) and smooth pursuit eye movement (MORL). The joint action of these three systems enables stabilization of the visual field in different situations of movement to which the subjects are submitted.

The term saccadic is defined as quick eye movement of high speed in hundreds of degrees/seconds and its purpose is to position the image of a visual field over the fovea ${ }^{1,2}$. There is still some controversy about the neural mechanisms involved in the execution of MOS, but recent studies indicated that the generator of horizontal movement is at the medullar point of the reticular formation, close to the abducens nucleus, whereas the generator of vertical movement is in the medium rostral reticular formation for the oculomotor nuclei ${ }^{3,4}$.

The movement of a visual scene through the visual field evokes involuntary and conjugated ocular movement, named optokinetic nystagmus. The optokinetic system operates with visual signals of the whole retina, not over the fovea ${ }^{1}$. Such system is closely related with the vestibular system, given that the real objective of the optokinetic system does not follow the movement of the visual scene whereas the observer remains stationary, but rather, supports the vestibular system during the movement of rotation, producing ocular movements that are appropriate to maintaining the image on the retina ${ }^{1}$. Both systems share the same objective to try to maintain the same speed in both eyes and against the speed of the head. This objective is achieved by the modification of the oculomotor response induced by vestibular-ocular reflexes and by optokinetic nystagmus, continuously and according to the speed of the visual and head fields ${ }^{2}$.Smooth pursuit eye movement is the mechanism, of oculomotor control that moves the eyes to stabilize the target image on the retina. Neural pathways involved in this movement go through the occipital cortex, temporal cortex, parietal cortex, corpus callosum, pons, bulb and cerebellum ${ }^{5}$.

The study of oculomotricity is important in the assessment of patients with dizziness, given that body balance is maintained by the interaction of the three systems: visual, labyrinth and proprioceptive. MOS, NO and MORL analysis is widely used to investigate the visual system and its contribution to the maintenance of balance. The study, therefore, is based on the otoneurological assessment of both adults and children.
As to adults, there are normal range values well determined in the literature for each test ${ }^{6}$. Thus, for saccadic eye movement, normal latency is between 180$250 \mathrm{mseg}$ and precision over $80 \%$. For optokinetic nystagmus, gain in speed of $30 \%$ sec is of about $0.740,17$ and for speed of $60 \% \mathrm{sec}$ it is about 0.890 .12 . The normal range for gain in pendular tracking of $0.95^{\circ}$ and degree of distortion is up to $10 \%$. However, concerning children, there are studies commenting about the affections to oculomotricity as a result of growing ${ }^{7-10}$, and others show that oculomotricity may help in diagnosing abnormalities 11, 12 and diseases ${ }^{13-15}$, but there are no reference test values to be used as baseline.

We know that there is influence of age on visual mechanisms of balance control ${ }^{16}$, such as for example, reduction in gain of optokinetic nystagmus in speed over $60^{\circ} / \mathrm{sec}$ in elderly subjects ${ }^{6}$. For this reason, the values of normal range in adults may be used to interpret exams in children.

\section{OBJECTIVE}

Given that we did not find any studies correlating normal results in adults and children, the present study intended to investigate saccadic eye pursuit movement, optokinetic nystagmus and smooth pursuit eye movements in normal children through measurements obtained with oculography and to compare the results with value found in normal adults (control group) and to confirm or not the feasibility of using the same normal range parameters in adults to interpret tests in children.

\section{MATERIAL AND METHOD}

We selected 50 children aged 5 to 10 years and 35 adults aged 22 to 50 years who had normal clinical history and physical examination, without data that suggested ocular pattern abnormalities.

The inclusion criteria were:

- Visual acuity and collaboration compatible with the requirements of the exam;

- Absence of dizziness complaints or signs or symptoms that could indicate abnormal vestibular function;

- Absence of history of neurological disease;

- Absence of extrinsic ocular motricity deficit or other abnormal ocular movements.

To perform the vestibular test we used a Belgium program ENG 290 MUMEDIA of computed vestibulometry, installed in a $386 \mathrm{PC}$, given that it is slow and could better show the tracing, with direct connection with a high-definition 20" TV monitor. The program enabled the examiner to control the presentation of stimulus in all tests and to make 
automatic quantitative calculations when assessing the performance. The exam comprised calibration of recording of saccadic eye pursuit movements, optokinetic nystagmus and smooth pursuit eye movements and the tests were performed in semi-dark room.

The calibration of ocular movements was made with horizontal movements, with $10^{\circ}$ intervals from the left to the right direction.

- Saccadic eye movement: the light target was displaced horizontally for 35 seconds, with amplitude of $20^{\circ}$. Patients were instructed to maintain the eyes on the light target, following any and all displacement. We studied precision and latency on the right and left.

- Optokinetic nystagmus: to stimulate, we used a picture of the world map vertically sectioned by black bars. The stimulus was presented in clockwise to anti-clockwise direction, for 10 seconds, amounting to a total of 60 seconds (three presentations in each direction). The speed of the stimuli was $30 \%$ s. The patient was instructed to look at the bars that passed on the TV screen, without fixing the eyes on any specific point. We studied right and left gain.

- Smooth pursuit eye movement: a light point, used for stimulation, made horizontal movements at constant speed. The recording time was $40 \mathrm{sec}$ for the used amplitude $\left(30.6^{\circ}\right)$. Patients were instructed to track the horizontal displacement of the light target. The studied aspects were right and left gain and distortion degree.

Some children showed difficulties to perform the latency and precision MOS test and the distortion degree of MORL, reason why the values were excluded from the analyses so that they would not interfere in the results.

The results obtained in the children's exams were compared to results of tests in adults. To statistically analyze the data we used t Student test.

\section{RESULTS}

We studied 50 children aged between 5 and 10 years (mean of 7.62 years), 22 female and 28 male children.

The group of adults was formed by 35 patients aged between 22 and 70 years (mean age of 37.6 years), 25 women and 10 men.

The values and the statistical analysis of data are presented in Tables 1 to 4 (saccadic eye movement), 5 and 6 (optokinetic nystagmus) and 7 to 9 (Smooth pursuit eye movement). For all studied variables, t Student test was significant at the level of $\Delta=0.05$, showing that the normal range for children was not similar to that in adults.

\section{DISCUSSION}

It is estimated that vestibular pathway myelinization of the vestibular pathways occurs at about 16 weeks and that pyramidal tracts are myalinized at the age of 24 months, and oculomotricity is finished at this time ${ }^{17}$. Thus, the investigation of MOS, NO and MORL can only be performed after the age of 2 years. Lewis et al. (2000) agree that as of the age of 2 years there has already been maturation of cortical pathways involved in $\mathrm{NO}^{18}$. Another study states that NO pathway maturation may occur at about the age of 7 years only for slow movements ${ }^{19}$. MORL is present at the age of 4 years, but they continue to develop as a result of aging ${ }^{7}$. However, they have already been identified in children aged 2 months, but gain increases as the child grows 8,9 . Thus, oculomotricity can already be performed in small children, and it is part of the investigation tests of the vestibular function. In our study, we included children older than 5 years because we had noticed that after this age they can better understand the exam, which enable more reliable results from the test.

As to adults, data on oculomotricity are expected to change as a result of aging and parameters found for elderly are different from those found in younger patients. This fact

Table 1. Saccadic eye movement: right precision in $\%$ in $20^{\circ}$ amplitude.

\begin{tabular}{lccccc}
\hline Variable: & & \multicolumn{2}{c}{ PRECD20 } & \multicolumn{2}{c}{ PRECD20 } \\
CLASS & $\mathrm{N}$ & Mean & Standard deviation & Error & Minimum \\
\hline ADULT & 35 & 90.60000000 & 12.70757069 & 2.14797149 & 60.00000000 \\
CHILD & 46 & 106.28260870 & 21.61343517 & 3.18672716 & 68.00000000 \\
\hline
\end{tabular}

Table 2. Saccadic eye movement: left precision in $\%$ in $20^{\circ}$ amplitude.

\begin{tabular}{lccccc}
\hline Variable: & & \multicolumn{2}{c}{ PRECE20 } & \multicolumn{2}{c}{ PRECE20 } \\
CLASS & $\mathrm{N}$ & Mean & Standard deviation & Error & Minimum \\
\hline ADULT & 35 & 94.20000000 & 12.19160753 & 2.06075779 & 70.00000000 \\
CHILD & 46 & 108.73913043 & 19.02446937 & 2.80500498 & 76.00000000 \\
\hline
\end{tabular}


was demonstrated in a study performed in our service 7 years ago ${ }^{16}$.

However, in children, data are scarce and many times insufficient. There are many studies that address the affection of oculomotricity as children get older ${ }^{7-10}$. Others believe that oculomotricity is important in detecting neurological anomalies ${ }^{11,12}$, or as support in the diagnosis of epilepsy ${ }^{13}$, as a screening method to detect visual or

Table 3. Saccadic eye movement: right latency in msec in $20^{\circ}$ amplitude.

\begin{tabular}{|c|c|c|c|c|c|c|}
\hline \multicolumn{2}{|l|}{ Variable: } & \multicolumn{3}{|c|}{ LATD20 } & \multicolumn{2}{|c|}{ LATD20 } \\
\hline CLASS & $\mathrm{N}$ & Mean & Standard deviation & Error & Minimum & Maximum \\
\hline$\overline{\mathrm{ADULT}}$ & 35 & 194.48571429 & 41.05116709 & 6.93891371 & 97.00000000 & 253.00000000 \\
\hline CHILD & 46 & 366.82608696 & 318.07848817 & 46.89811451 & 60.00000000 & 1955.00000000 \\
\hline
\end{tabular}

Table 4. Saccadic eye movement: left latency in msec in $20^{\circ}$ amplitude.

\begin{tabular}{lccccc}
\hline $\begin{array}{l}\text { Variable: } \\
\text { CLASS }\end{array}$ & $\mathrm{N}$ & Mean & Standard deviation & Error & LATE20 \\
ADULT & 35 & 180.85714286 & 32.96802627 & 5.57261353 & 127.00000000 \\
CHILD & 46 & 358.41304348 & 304.14087205 & 44.84312512 & 82.00000000 \\
\hline
\end{tabular}

Table 5. Optokinetic nystagmus: right gain in $\%$ in $30 \%$ speed.

\begin{tabular}{lccccr}
\hline $\begin{array}{l}\text { Variable: } \\
\text { CLASS }\end{array}$ & $\mathrm{N}$ & Mean & Standard deviation & Error & GAND30 \\
\hline ADULT & 35 & 82.52857143 & 12.22075312 & 2.06568430 & 47.90000000 \\
CHILD & 50 & 106.09800000 & 34.59621007 & 4.89264295 & 56.20000000 \\
\hline
\end{tabular}

Table 6. Optokinetic nystagmus: left gain in $\%$ in $30 \%$ speed.

\begin{tabular}{lccccc}
\hline $\begin{array}{l}\text { Variable: } \\
\text { CLASS }\end{array}$ & $\mathrm{N}$ & Mean & Gtandard deviation & Error & GANE30 \\
\hline ADULT & 35 & 80.11142857 & 12.72671510 & 2.15120748 & 54.70000000 \\
CHILD & 50 & 103.77000000 & 28.96063655 & 4.09565250 & 67.80000000 \\
\hline
\end{tabular}

Table 7. Smooth pursuit eye movement: level of distortion in $\%$ in $30.6^{\circ}$ amplitude.

\begin{tabular}{lccccc}
\hline Variable: & & \multicolumn{2}{c}{ GRD306 } & & GRD306 \\
CLASS & $\mathrm{N}$ & Mean & Standard deviation & Error & Minimum \\
\hline ADULT & 35 & 5.77714286 & 6.00328761 & 1.01474081 & 0.70000000 \\
CHILD & 43 & 37.49534884 & 25.43793524 & 3.87924876 & 4.70000000 \\
\hline
\end{tabular}

Table 8. Smooth pursuit eye movement: right gain in $\%$ in $30.6^{\circ}$ amplitude.

\begin{tabular}{lccccc}
\hline $\begin{array}{l}\text { Variable: } \\
\text { CLASS }\end{array}$ & $\mathrm{N}$ & Mean & Standard deviation & Error & GD306 \\
\hline ADULT & 35 & 85.06285714 & 17.15263804 & 2.89932500 & 55.80000000 \\
CHILD & 50 & 54.79400000 & 22.67119372 & 3.20619096 & 128.70000000 \\
\hline
\end{tabular}

Table 9. Smooth pursuit eye movement: left gain $\%$ in $30.6^{\circ}$ amplitude.

\begin{tabular}{lccccc}
\hline $\begin{array}{l}\text { Variable: } \\
\text { CLASS }\end{array}$ & $\mathrm{N}$ & Mean & Standard deviation & Error & GE306 \\
\hline ADULT & 35 & 81.54285714 & 18.50002044 & 3.12707420 & 47.80000000 \\
CHILD & 50 & 53.96800000 & 22.17306180 & 3.13574447 & 125.20000000 \\
\hline
\end{tabular}


cerebral function ${ }^{14}$, to assess children with schizophrenia ${ }^{15}$, and also for the detection of genetic risk for the development of the disease ${ }^{20}$, but these studies do not show numbers that may be used as normal values.

Our study, upon comparing oculomotricity in normal children and adults, showed that there are differences between the two groups. A study performed by Levens (1988) clearly described the differences that may occur in electronystamographic tracings in adults and in children; however, no tests for oculomotricity were performed ${ }^{21}$.

In MOS study, we found increase in latency both on the right and on the left in children compared with adults. It is in agreement with what was described by Kowler \& Martins (1982), but these authors studied only children aged 4 to 5 years ${ }^{22}$. We would like to point out that we reached a high standard deviation in the analysis of this variable and it is probably due to attention deficit that children had in the exam, a fact that should attract the attention of the examiner. MOS precision was higher in the group of children in the right and also on the left and we did not find any explanation to this fact.

The assessment of NO in the study showed that children present higher gain than adults on the right and on the left. These data differ from the study by Sakaguchi et al. (1997) who found differences in values of gain in children and adults only when the test was performed in the dark ${ }^{23}$. For a test performed in semi-dark, there was no difference between the two groups. Our tests were always performed in semi-dark rooms.

MORL investigation showed lower gain on the right and also on the left for children in comparison to adults. Accardo et al. (1995) has also described it in their study and attributed this finding to psychological and cognitive factors and also to incomplete maturation of MORL systems in children ${ }^{24}$. In our study, we found some level of distortion in children, which was attributed to the same factors, in addition to the attention deficit they had in the exam and it was in agreement with the study by Snashall (1983) that states that lack of attention and immaturity in the control of eye movements creates difficulties in the analysis of oculography 25 .

\section{CONCLUSION}

The analysis of saccadic eye movements, optokinetic nystagmus and smooth pursuit eye movements in 50 healthy children and in 35 healthy adults led us to the conclusion that acceptable normal parameters for the adult population should not be used in the interpretation of tests in children and new studies are required to define the normal range of oculomotricity in this group so that these tests can be used in the assessment of different and important clinical conditions that affect the pediatric population.

\section{REFERENCES}

1. Moreira MMF, Maudonnet OAQ. Conceitos e funções dos movimentos oculares de rastreio lento sacádico e nistagmo optocinético. Acta AWHO 1998; 17(3): 135-8.

2. Dufour A, Mira E, Pignataro O. Otoneurologia clínica. Milão: CRS $245 ; 1993$.

3. Morrow MJ \& Sharpe J. Smooth pursuit eye movement. In: Sharpe JA \& Barber HO. The vestibulo-ocular reflex and vertigo New York: Raven Press; 1993. p.141-62.

4. Moreira MMF, Maudonnet OAQ. Neurofisiologia dos movimentos oculares. Acta AWHO 1998; 17(4): 213-2.

5. Maudonnet OAQ. Anátomo-fisiologia da ocuolomotricidade. In: . Avaliação Otoneurológica. $1^{\text {a }}$ ed. São Paulo: Editora BYK; 1999. p. 30.

6. Maudonnet OAQ. Vestibulometria computadorizada. Ver Bras ORL 1985; (1) 61 49-57.

7. Tajik-Parvinchi DJ, Lillakas L, Irving E, Steinbach MJ. Children's pursuit eye movements: a developmental study. Vision Res 2003; 43(1): 77-84.

8. Jacobs M, Harris C.M, Shawkat F, Taylor D. Smooth pursuit development in infants. Aust N Z J Ophtalmol 1997; 25(3): 199206.

9. Von Hofsten C \& Rosander K. Development of smooth pursuit tracking in young infants. Vision Res 1997; 37(13): 1799-810.

10. Ross RG, Radant AD, Hommer DW. A developmental study of smooth pursuit eye movements in normal children from 7 to 15 years of age. Am Acad Child Adolesc Psychiatry 1993; 32(4): 783-91.

11. Garbutt S \& Harris CM. Abnormal vertical optokinetic nystagmus in infants and children. Br J Ophtalmol 2000; 84(5): 451-5.

12. Shawkat FS, Kingsley D, Kendall B, Russel-Eggitt I, Taylor DS, Harris CM. Neuroradiological and eye movement correlates in children with intermittent failure: "ocular motor apraxia". Neuropediatrics 1995; 26(6): 298-305.

13. Pawlak-Osinska K, Kazmierczak H, Kuczynska R, Osinski P, Kasprowicz E, Slaboszewska K. Vestibular findings in children's epilepsy. Otolaryngol Pol 1999; 53(4): 479-83.

14. Schwarzbach M \& Schwartze P. Induction of optokinetic nystagmus in infants and young children by a horizontally diagonally or vertically moving striped pattern. Padiatr Grenzgeb 1991; 30(3): 167-82.

15. Jacobsen LK, Hong WL, Hommer DW, Hamburger SD, Castellanos FX, Frazier JA, Giedd JN, Gordon CT, Karp BI, Mckenna K, Rapoport JL. Smooth pursuit eye movements in childhood-onset schizophrenia: comparison with attention-deficit hyperactivity disorder and normal controls. Biol Psychiatry 1 1996; 40(11): 1144-54.

16. Fonseca MM. Movimentos oculares de rastreio lento sacádicos e nistagmo optocinético em adultos normais. Campinas 1977. Tese de Mestrado - Universidade Estadual de Campinas.

17. Ganança FF \& Ganança CF. Vertigem na infância e na adolescência. In: Ganança MM. Vertigem tem cura? São Paulo: Lemos Editorial; 1998. p. 38-9.

18. Lewis TL, Maurer D, Chung JY, Holmes-Shannon R, Van Schaik $\mathrm{CS}$. The development of symmetrical OKN in infants: quantification based on OKN acuity for nasalward versus temporalward motion. Vision Res 2000; 40(4): 445-53.

19. D'agostino R, Melagrana A, Pasquale G, Taborelli G. The study of optokinetic "look" nystagmus in children: our experience. Int J Pediatr Otorhinolaryngol 1997; 20; 40(2-3): 141-6.

20. Ross RG, Hommer D, Radant A, Roath M, Freedman R. Early expression of smooth-pursuit eye movement abnormalities in children of schizophrenic parents. Am Acad Chil Adolesc Psychiatry 1996; 35(7): 941-9.

21. Levens SL. Eletronystagmography in normal children. Br J Audiol 1988; 22(1): 51-6. 
22. Kowler E \& Martins AJ. Eye movements of preschool children. Science 1982; 19; 215 (4535): 997-9.

23. Sakaguchi M, Taguchi K, Sato K, Akahira T, Netsu K, Katsuno S, Ishiyama T. Vestibulo-ocular reflex and visual vestibulo-ocular reflex during sinusoidal rotation in children. Acta Otolaryngol Suppl 1997; 528: 70-3.
24. Accardo AP, Pensiero S, Da Pozzo S, Perissutti P. Characteristics of horizontal smooth pursuit eye movements sinusoidal stimulation in children of primary school age. Vision Res 1995; 35(4): 53948.

25. Snashall SE. Vestibular function tests in children. J R Soc Med 1983; 76(7): 555-9.

Brazilian Journal of Otorhinolaryngology 71 (5) Part 1 September/October 2005 